\title{
Konsep desain taman terapi paru di Rumah Sakit Paru Dungus, Kabupaten Madiun, Provinsi Jawa Timur
}

\author{
Dwi Ulul Asmi1 ${ }^{1}$, Naniek Kohdrata ${ }^{1}$, I Nyoman Gede Astawa ${ }^{2}$
}

1. Prodi Arsitektur Pertamanan, Fakultas Pertanian, Universitas Udayana, Indonesia 80236

2. Prodi Agroekoteknologi, Fakultas Pertanian, Universitas Udayana, Indonesia 80236

*E-mail: naniek_kohdrata@unud.ac.id

\begin{abstract}
The lung therapeutic garden conceptual design at Dungus Lung Hospital at Madiun Regency East Java Province. Dungus Lung Hospital of Madiun Regency is a health care center that treats patients who have respiratory disease and general illnesses. An approach that can be given to help healing process of respiratory disease is the psychological and physiological through of The Lung Therapeutic Garden. The therapeutic garden uses concepts and elements of a garden appropriate for respiratory distress therapy. The concept applies to The Lung Therapeutic Garden is healing environment by applying garden elements such a natural hardscape like a rocks and woods, and softscape like water and colored plants, textured plants, and fresh scent flowering plants. The Lung Therapeutic Garden at Dungus Lung Hospital is based on Marcus' therapeutic rationale. The aims of this study is to design a lung therapeutic garden. The method used in this research was field survey based on Rachman's complete thinking process (1984). Furthermore, this research data will be aligned with the Time Saver Standards for Landscape Architecture in planning and designing The Lung Therapeutic Garden. The result of this study is the concept of healing environment that suitable to be applied to help healing process of respiratory distress. This is according to patient's need for clean air with adequate oxygen concentration and sunlight. The application of natural hardscape and softscape as objects of therapy can assist the healing process by stimulating human senses.
\end{abstract}

Keywords: therapeutic garden, lung therapeutic garden, respiratory therapy

\section{Pendahuluan}

Paru merupakan organ pernapasan yang sangat vital bagi kelangsungan hidup manusia. Namun, angka morbiditas (kesakitan) yang disebabkan oleh gangguan pernapasan di Provinsi Jawa Timur cukup tinggi (Dinkes Jatim, 2012). Salah satu tindakan yang dapat dilakukan dalam proses penyembuhan penyakit gangguan pernapasan yakni melalui pendekatan secara medis berupa farmakoterapi dan fisioterapi. Desain taman terapi merupakan salah satu bentuk pendekatan alternatif yang dapat dilakukan dalam proses penyembuhan penyakit gangguan pernapasan.

Rumah Sakit (RS) Paru Dungus belum memiliki taman terapi. Keberadaan taman ini sangat penting guna membantu proses penyembuhan serta memberikan pengalihan yang positif bagi pasien, pengunjung, maupun pegawai RS yang setiap hari berada di dalam ruangan. Menurut Marcus (2007), taman terapi fokus pada pelepasan stres, meringankan gejala fisik, dan meningkatkan perasaan yang lebih baik bagi pasien, pengunjung, dan pegawai RS. Taman yang mampu menyembuhkan adalah taman yang memiliki sifat alami dengan kehadiran tanaman dan atau fitur air. Kebutuhan tersebut dapat dipenuhi melalui konsep dan model desain, serta elemen taman yang sesuai bagi penderita gangguan pernapasan di RS Paru Dungus.

\section{Metode Penelitian}

\subsection{Waktu dan Lokasi Penelitian}

Penelitian ini dilaksanakan selama 7 bulan di RS Paru Dungus Kecamatan Wungu Kabupaten Madiun Jawa Timur (Gambar 1). 


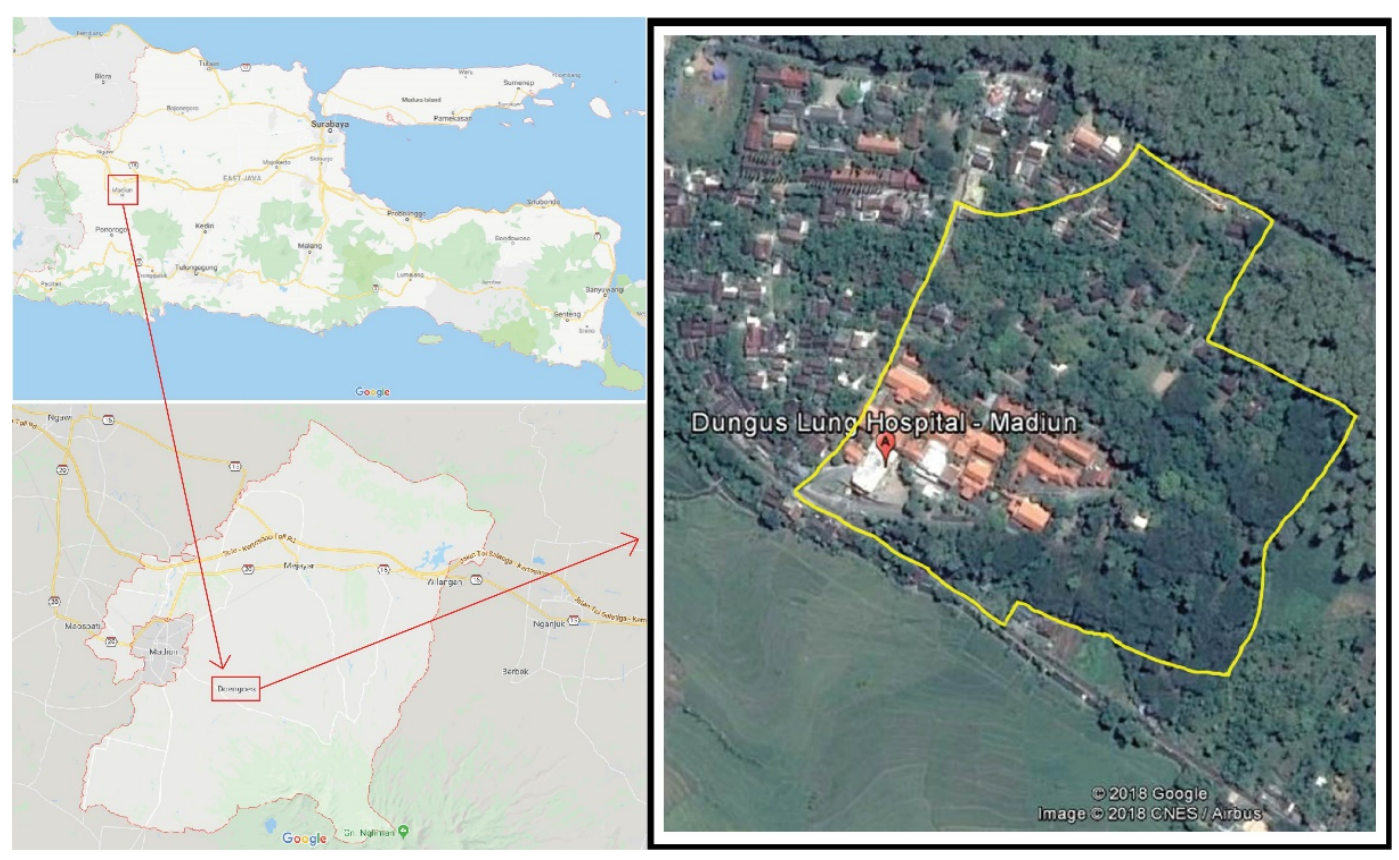

Gambar 1. Peta Lokasi Penelitian

\subsection{Metode Penelitian}

(Sumber: Google Map, 2019 dan Google Earth, 2018)

Penelitian ini dilakukan dengan metode survei mengikuti proses berpikir lengkap menurut Rachman (1984) yaitu dengan tahapan inventarisasi, analisis, sintesis, konsep, perencanaan, dan desain. Pengumpulan data dilakukan melalui wawancara, observasi, pengukuran, dan studi pustaka. Data yang ada dalam penelitian ini diselaraskan dengan standar pada Time Saver Standards for Landscape Architecture yang menjadi acuandan pedoman dalam merencanakan dan mendesain Taman Terapi Paru.

\section{Hasil dan Pembahasan}

\subsection{Gambaran Umum RS Paru Dungus}

RS Paru Dungus berlokasi di Jalan Raya Dungus, Kecamatan Wungu, Kabupaten Madiun. Jarak RS Paru Dungus dari pusat Kota Madiun kurang lebih $14 \mathrm{~km}$. Saat penelitian dilakukan, transportasi umum menuju RS Paru Dungus belum tersedia. Total luas lahan yang dimiliki RS Paru Dungus adalah $81.129 \mathrm{~m}^{2}$ dengan luasan terbangun mencapai $29.360 \mathrm{~m}^{2}$. Lokasi tapak untuk Taman Terapi Paru menggunakan lokasi yang telah ditunjuk dalam Masterplan RS Paru Dungus tahun 2016-2036 (Gambar 2).

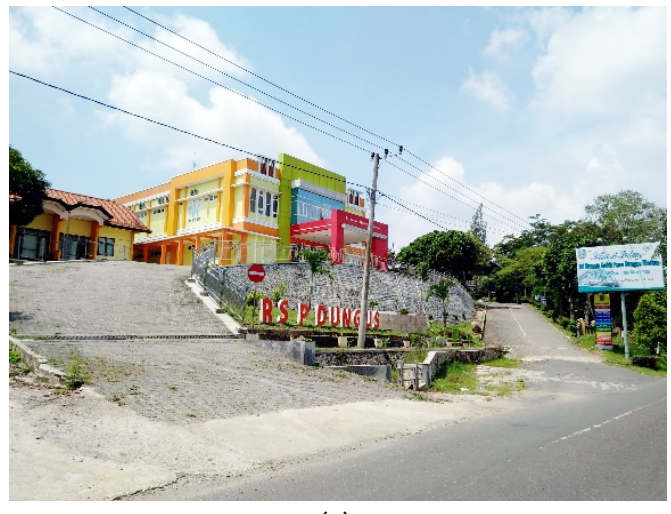

(a)

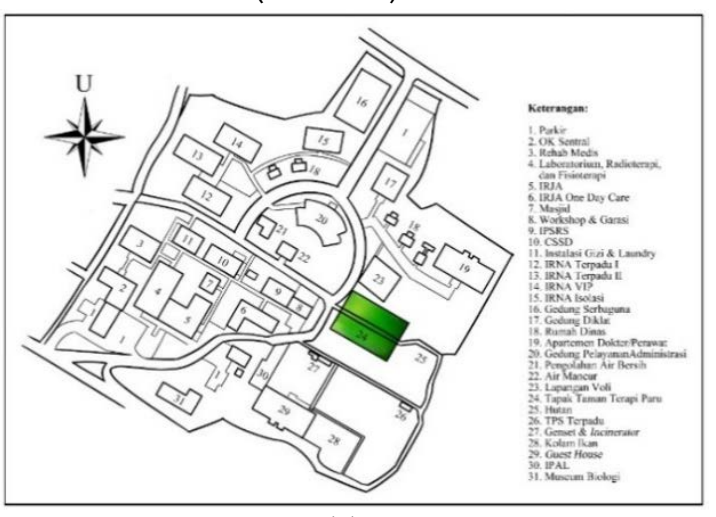

(b)

Gambar 2. Peta dan gambar orientasi RS Paru Dungus

(a) RS Paru Dungus; (b) Tapak lokasi Taman Terapi Paru 


\subsection{Aspek Biofisik}

\subsubsection{Lokasi dan Aksesibilitas}

Lokasi taman terapi yang direncanakan sesuai dengan Masterplan RS Paru Dungus tahun 2016 -

2036. Taman terapi tersebut berada di sebelah timur rumah sakit berbatasan dengan lapangan voli di sisi utara, gedung IPSRS (Instalasi Pemeliharaan Sarana dan Prasarana Rumah Sakit) di sisi barat, genset dan incinerator di sisi selatan, dan hutan di sisi timur.

Kendala yang ada pada tapak adalah lokasinya yang cukup jauh dari gedung IRNA (Instalasi Rawat Inap) dan IRJA (Instalasi Rawat Jalan). Lokasi tersebut tidak diatur ulang untuk ditempatkan dekat dengan IRNA dan IRJA sebab telah ada bangunan lain dan beberapa bangunan yang sedang dibangun didekatnya. Keberadaan genset dan incinerator di sisi selatan berpotensi menghasilkan polusi suara ketika digunakan. Untuk meredam polusi tersebut, maka ditempatkan tanaman-tanaman yang mampu meredam suara dengan cara mengabsorbsi gelombang suara melalui daun, cabang, dan ranting yaitu tanaman yang memiliki tajuk tebal dan berdaun lebat seperti tanaman bambu.

Lokasi tapak juga memiliki potensi yaitu letak yang strategis berada di tepi jalan utama rumah sakit sehingga mudah ditemukan dan diakses oleh pasien, pegawai dan pengunjung rumah sakit. Potensi lainnya adalah tapak berbatasan langsung dengan hutan, sehingga ekosistem tapak dan hutan dapat dihubungkan secara langsung guna memenuhi elemen desain taman berupa fitur taman yang menarik serta mampu menyediakan habitat bagi keanekaragaman satwa lokal.

\subsubsection{Topografi}

Kecamatan Wungu terletak pada ketinggian 10-500m dpl. Lahan RS Paru Dungus berada pada ketinggian 240-280m dpl (Pokja Sanitasi Kab. Madiun dan Google Earth, 2018). Topografi berteras semakin rendah kearah selatan. Bangunan RS Paru Dungus berada di dataran menengah yang jauh dari hiruk pikuk perkotaan. Kondisi udara di sekitar RS yang masih segar dan rendah polusi menjadikannya sebagai tempat yang ideal untuk proses pengobatan, perawatan, dan pemulihan bagi penderita gangguan pernapasan.

Tapak Taman Terapi Paru memiliki dua elevasi yang berbeda dengan selisih \pm 1 meter. Kondisi ini dapat dimanfaatkan sebagai media latihan ringan dengan menghadirkan rem dan tangga bagi pengguna tapak. Perbedaan elevasi dipertahankan dengan tujuan untuk memberi kesan dinamis dan meminimalkan kemonotonan serta untuk menjaga tapak agar terhindar dari ancaman erosi.

\subsubsection{Tanah}

Berdasarkan peta jenis tanah, Kecamatan Wungu memiliki jenis tanah latosol bertekstur halus (Pokja Sanitasi Kab. Madiun, 2011). Tanah latosol memiliki tekstur granular, stabilitas agregat yang tinggi, kepekaan terhadap erosi rendah, memiliki permeabilitas dan drainase dalam yang baik (Azizi, 1995). Solum tanah latosol lebih dari $150 \mathrm{~cm}$ dan memiliki kejenuhan basa kurang dari 50\%. Kondisi tanah tersebut merupakan sebuah potensi sebab memiliki sifat fisik, kimia, dan biologis yang baik sehingga sebagian besar tanaman dapat dibudidayakan pada tanah latosol, seperti pohon kesambi, cempaka, kayu putih, bambu, cemara, adas, melati, jeruk, nilam, dan serai.

\subsubsection{Hidrologi}

Air bersih yang digunakan di RS Paru Dungus bersumber dari PDAM dan waduk yang ada di dekat rumah sakit. Kebutuhan air ditampung dalam bak penampung berkapasitas $\pm 9,2 \mathrm{~m}^{3}$ kemudian dialirkan menuju tandon air untuk didistribusikan pada setiap instalasi rumah sakit melalui saluran pipa. Air limbah RS Paru Dungus diolah pada Instalasi Pengolahan Air Limbah (IPAL) di sisi tenggara yang disalurkan melalui tiga drainase yaitu drainase primer, sekunder, dan tersier. Seluruh drainase menggunakan sistem terbuka guna memudahkan pembersihan dan pemeliharaan (Empat Pilar Konsultan, 2016).

RS Paru Dungus menggunakan sumber air PDAM dan air dari waduk yang jumlahnya terbatas. Penggunaan air secara efektif dan efisien perlu diterapkan agar tidak terjadi pemborosan dalam pemakaian air bersih. Salah satu upaya yang dapat dilakukan adalah menerapkan irigasi tetes, yaitu sistem pengairan menggunakan aliran rendah yang langsung menuju tanah dan mengairi akar tanaman dengan efisien. Hal ini dapat menekan penggunaan air, namun biaya pengadaan irigasi tetes lebih mahal. Masalah yang dapat terjadi adalah penyumbatan pada nozzle apabila tidak dilakukan pemasangan yang tepat dan perawatan yang teratur. Upaya lain yang dapat dilakukan adalah dengan menggunakan kembali air limbah rumah sakit yang telah diolah dan tidak melebihi batas baku mutu lingkungan yang telah ditetapkan. 


\subsubsection{Iklim}

Kabupaten Madiun memiliki tipe iklim C yaitu beriklim sedang menurut tipe iklim Schmidt and Fergusson. Kisaran suhu berada pada $24^{\circ} \mathrm{C}$ dengan kelembaban rata-rata $75 \%$ dan radiasi matahari $74,1 \%$ (BPS Kab. Madiun, 2016). Kondisi lingkungan yang dibutuhkan oleh pasien gangguan pernapasan untuk membantu proses penyembuhannya yaitu lingkungan yang menyediakan cukup sinar matahari, udara yang sejuk dan tingkat kelembaban yang rendah (Hanik dan Nita, Komunikasi Pribadi, 19 April, 2017).

Kebutuhan akan sinar matahari yang cukup dan udara sejuk dapat disiasati dengan menempatkan pohon yang memiliki tajuk lebar dan berdaun jarang sehingga sinar matahari masih dapat masuk melalui celah ranting pohon. Pengaturan pemecah angin pada tapak juga perlu diterapkan untuk mengatur sirkulasi angin agar tidak ada titik yang terblokir guna mencapai kondisi yang nyaman bagi pengguna taman.

\subsubsection{Vegetasi dan Satwa}

Vegetasi yang memenuhi tapak Taman Terapi Paru berupa semak belukar dan pohon-pohon lokal seperti; sengon (Albizia falcataria), jambu monyet (Anacardium occidentale), johar (Senna siamea), mangga (Mangifera indica), kesambi (Schleicera oleosa), dan jati (Tectona grandis). Satwa yang banyak dijumpai pada tapak adalah kupu-kupu dan burung.

Penggunaan tanaman lokal sebagai elemen desain bertindak sebagai penyangga lingkungan yang mampu mempengaruhi iklim, aliran air, pemandangan, marga satwa, dan keindahan (Dines dan Brown, 2001). Tanaman memiliki berbagai fungsi, salah satunya adalah fungsi ekologis yakni kemampuan menyerap debu seperti pohon sengon; menyerap $\mathrm{NO}_{2}$ yaitu pohon kayu putih dan johar; dan kemampuan mereduksi $\mathrm{CO}_{2}$ seperti trembesi, jati, dan johar (Santoso, 2011). Selain fungsi ekologis, tanaman juga memiliki fungsi estetika seperti fungsi penutup tanah, tanaman pagar, tanaman pelindung, tanaman memanjat, tanaman tabir, dan tanaman pengarah jalan.

Tanaman mampu memberi kesan keras, kuat, dan abadi. Kesan tersebut dapat tercipta melalui bentuk atau warna tanaman. Bentuk-bentuk yang mampu memberikan kesan positif adalah bentuk olakanolakan keatas (upwardswirls), piramida, gelembung-gelembung, dan lengkung-lengkung gothic (Irawan dan Priscilla, 2013). Sedangkan warna yang yang mampu memberikan pengaruh tenang, ceria, dan hangat adalah warna kuning dan putih, untuk meningkatkan konsentrasi yaitu warna hijau, kemudian warna pink dan merah mampu memberi kesan kuat, semangat, dan fantasi (Jongyun, et al., 2014).

\subsection{Aspek Sosial}

Lingkup aspek sosial yang dimaksud berupa aktivitas pasien dan pengunjung RS Paru Dungus. Pasien gangguan pernapasan dikategorikan menjadi tiga tingkatan yaitu rendah, sedang, dan tinggi yang akan mempengaruhi kemampuan aktivitas dan tindakan medis yang diberikan. Tindakan medis yang dimaksud adalah farmakoterapi dan fisioterapi yang umumnya diberikan pada pasien di RS Paru Dungus berupa nebulizer, terapi dada (breathing exercise, postural drainage, dan huffing), walking exercise (six minute walking test, static cycle) dan senam. Tindakan medis tersebut dilakukan pada pasien yang menderita Asma, COPD (Chronic Obstructive Pulmonary Disease), Tuberkulosa, dan Pneumotoraks (Nita, Wawancara Pribadi, 19 April, 2017). Beberapa dari tindakan tersebut dapat diadopsi pada desain Taman Terapi Paru melalui aktivitas fisik sebagai bentuk bagian dari fisioterapi luar ruangan yaitu six minute walking test, static cycle, treadmill, dan senam.

Pengunjung RS Paru Dungus umumnya adalah sanak keluarga pasien yang tidak jarang membawa serta anak-anak mereka. Pengunjung tersebut menghabiskan waktu di sepanjang selasar RS, tidak banyak kegiatan yang dapat dilakukan. Oleh sebab itu, keberadaan Taman Terapi Paru perlu untuk diterapkan pada RS Paru Dungus. Selain sebagai sarana penunjang proses penyembuhan juga dapat digunakan sebagai area alternatif untuk melepas stres kerja, dan kepenatan yang dirasakan oleh pegawai maupun pengunjung rumah sakit.

\subsection{Konsep}

\subsubsection{Konsep Dasar}

Konsep ini dibagi menjadi konsep dasar dan konsep pengembangan. Konsep dasar yang diterapkan pada RS Paru Dungus yaitu healing environment. Dasar pemikiran yang digunakan adalah model desain menurut Marcus (2007) (Gambar 3) yang menekankan akan rasa familiar sehingga menumbuhkan rasa nyaman bagi penggunanya. Penerapan konsep tersebut melalui prinsip desain dan elemen desain. 
Pertimbangan dalam pemilihan penggunaan elemen taman berupa elemen keras dan elemen lunak berdasarkan kemampuannya dalam membantu proses penyembuhan pada pasien gangguan pernapasan.

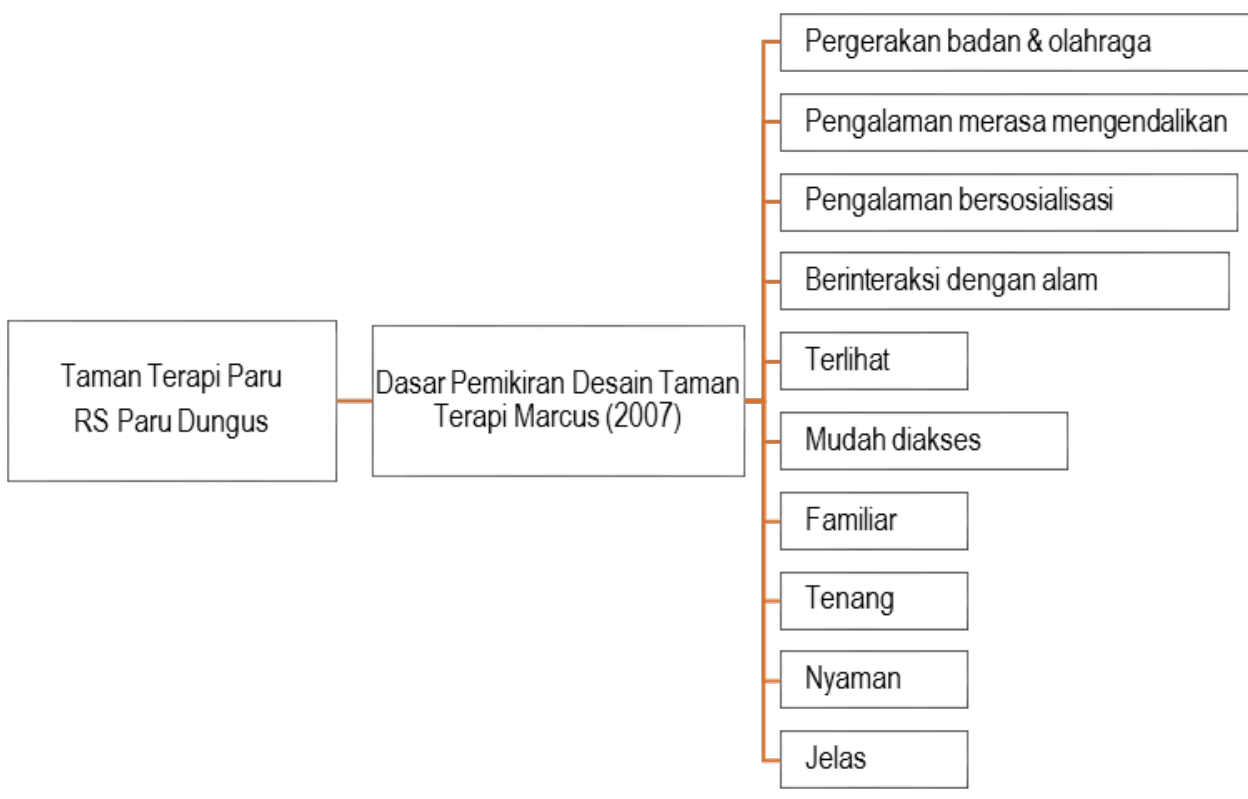

Gambar 3. Konsep Dasar Taman Terapi Paru

(Sumber: Marcus 2007, dengan pengolahan)

\subsubsection{Konsep Pengembangan}

Konsep pengembangan yang diterapkan pada Taman Terapi Paru di RS Paru Dungus merupakan bentuk penjabaran dari konsep dasar. Terdapat tiga konsep pengembangan yang didesain untuk taman terapi paru di RS Dungus, yaitu tata ruang, sirkulasi, dan tata hijau.

Ruang pada Taman Terapi Paru dibagi berdasarkan bentuk kegiatannya yaitu, zona aktif dan zona pasif. Model sirkulasi yang diterapkan pada Taman Terapi Paru menggunakan model cul-de-sac. Sirkulasi dengan model cul-de-sac memiliki satu pintu masuk yang juga berfungsi sebagai pintu keluar yang bertujuan agar memudahkan pengawasan terhadap pengguna taman. Konsep tata ruang dan sirkulasi tampak seperti pada Gambar 4.

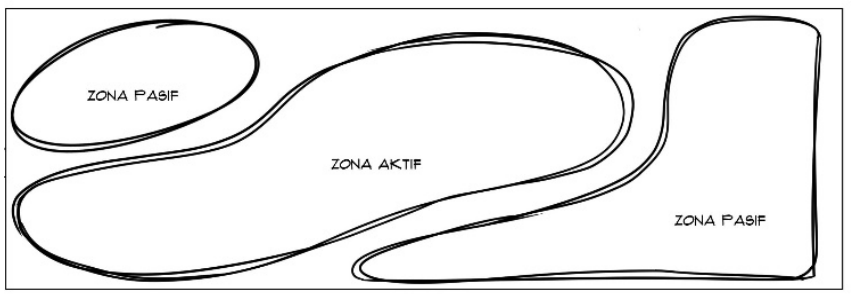

(a)

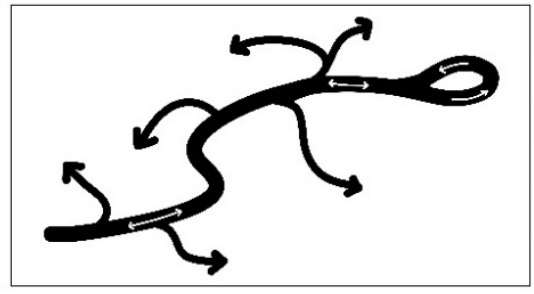

(b)

Gambar 4. (a) Konsep Tata Ruang

(b) Konsep Sirkulasi

Tanaman yang digunakan memiliki fungsi sebagai peneduh, pembatas, pengarah, penutup tanah, dan estetika. Strata tanaman yang digunakan yaitu pohon, semak, dan penutup tanah. Tanaman yang dipilih harus memenuhi karakteristik tanaman yang baik dalam mendukung proses penyembuhan penderita gangguan pernapasan. Tanaman yang memiliki aroma lembut, tanaman bertekstur, dan tanaman yang memiliki warna-warna indah dipilih sebagai objek terapi untuk merangsang indera manusia. Konsep tata hijau pohon, semak, dan penutup tanah ditunjukkan pada Gambar 5. 


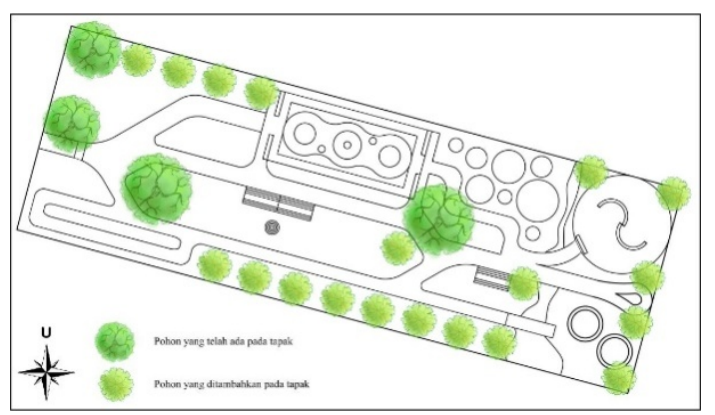

(a)

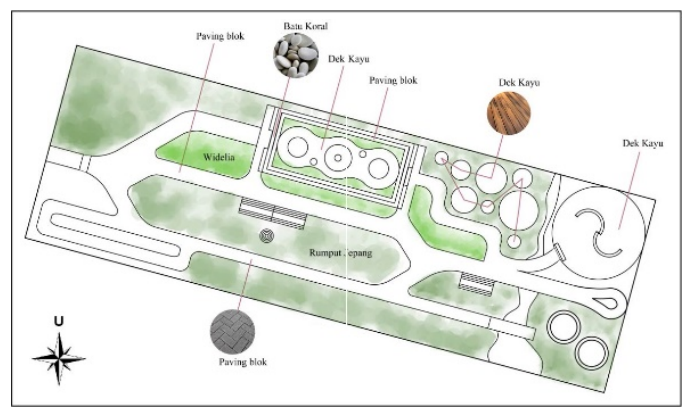

(b)

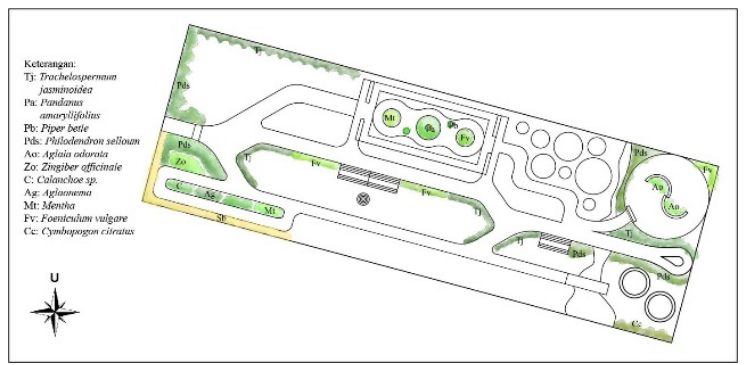

(c)

Gambar 5. (a) Konsep Tata Hijau Pohon

(b) Konsep Penutup Tanah; (c) Konsep Tata Hijau Semak

\subsection{Konsep Desain}

\subsubsection{Ruang dan Sirkulasi}

Ruang-ruang pada tapak berdasarkan zona yang telah ditetapkan terdapat ruang penerimaan, observasi, walking track, senam, yoga, dan meditasi, sepeda statis, ruang untuk melatih indera, dan ruang untuk bersosialisasi.

Terdapat dua jenis sirkulasi pada tapak berdasarkan fungsi dan lebarnya. Sirkulasi primer memiliki lebar 2,4 meter dan untuk sirkulasi sekunder 1,2 meter. Sirkulasi primer menghubungkan dua elevasi yang berbeda pada tapak yang ada di sebelah utara dan selatan. Kemudian sirkulasi sekunder menghubungkan antar ruang yang ada pada tapak seperti yang ditunjukkan pada Gambar 6.

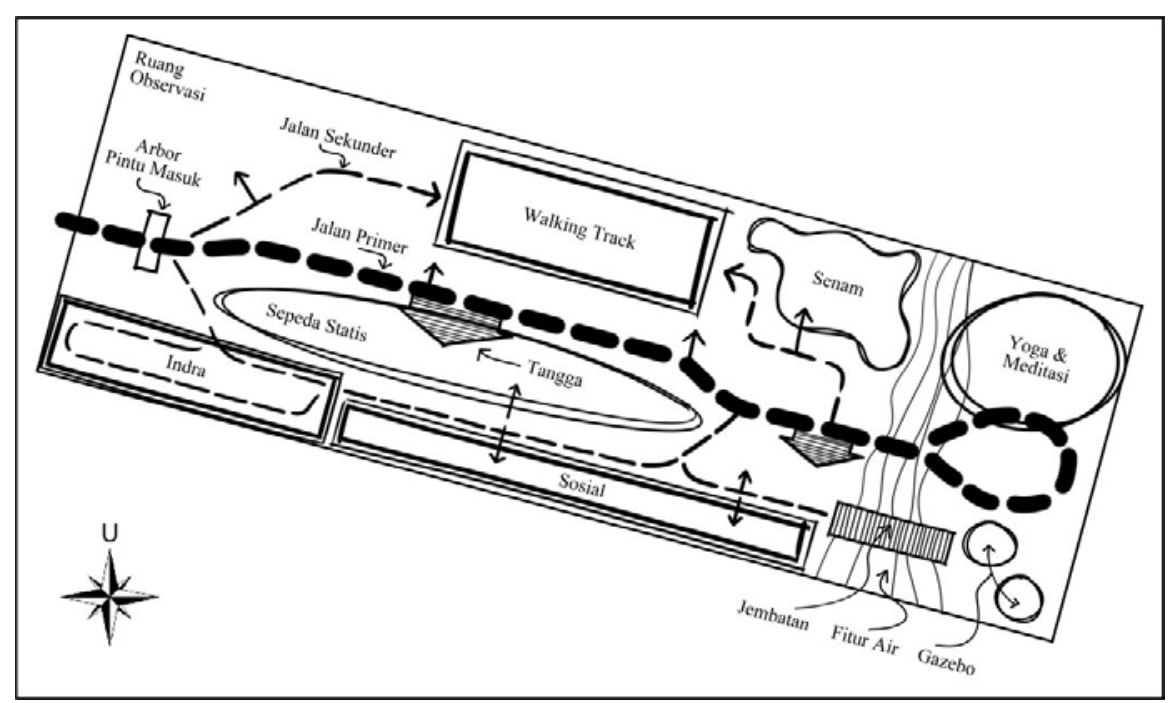

Gambar 6. Konsep Ruang dan Sirkulasi 


\subsubsection{Pemodelan Desain Penanaman}

Keberadaan tanaman berperan dalam memberikan kenyamanan dan membantu proses healing pada pengguna taman. Penanaman pohon, semak, dan penutup tanah ditanam berdasarkan fungsinya sebagai peneduh, pembatas, pengarah, penutup tanah, dan estetika. Tanaman-tanaman tersebut diaplikasikan pada masing-masing ruang sesuai dengan fungsi dan peruntukkannya (Gambar 7).

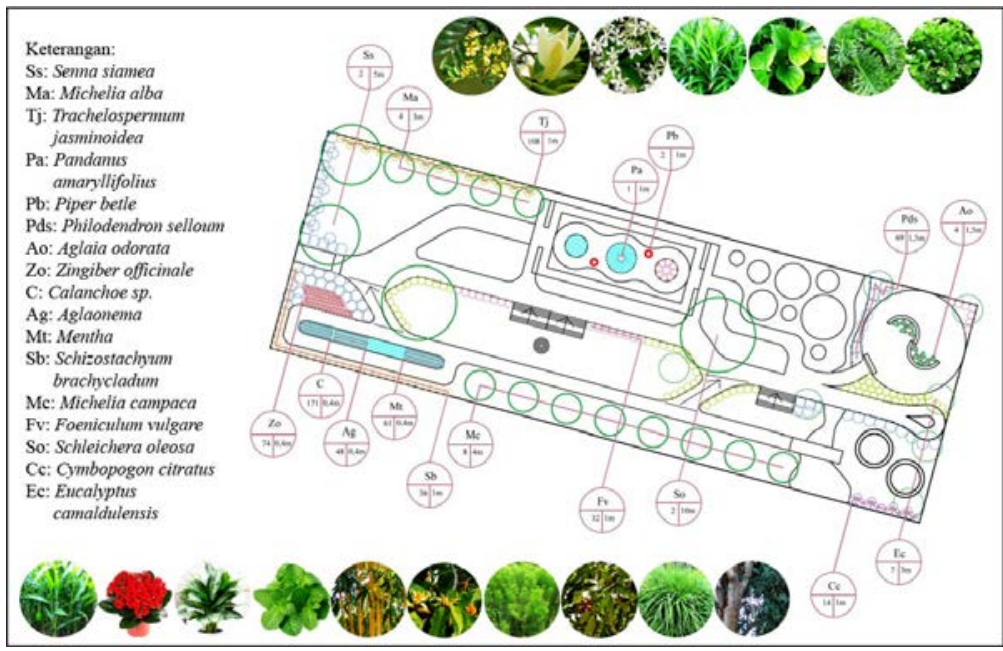

\subsubsection{Fasilitas dan Utilitas}

Gambar 7. Pemodelan Desain Penanaman

Fasilitas dan utilitas yang digunakan pada tapak berupa bangku taman, gazebo, arbor, jembatan, kolam, air mancur, dan lampu taman yang bertujuan untuk menunjang aktifitas pengguna taman. Bangku taman yang digunakan ditempatkan pada ruang observasi dan ruang sosial. Bangku taman di ruang sosial ditempatkan pada jarak zona personal yaitu 0,5 - 1,5 meter dengan tujuan agar pengguna tapak dapat berinteraksi dengan baik. Sedangkan pada ruang observasi, bangku ditempatkan pada zona sosial yaitu 1,5 - 3 meter agar ketenangan tetap terjaga. Meja dan bangku taman yang digunakan memiliki bentuk dinamis bertujuan untuk menjaga keselamatan penggunanya (Gambar 8). Penggunaan fasilitas arbor pada taman berfungsi sebagai penarik perhatian, diletakkan pada pintu masuk taman dan ruang meditasi. Lampu taman yang berfungsi sebagai sumber penerangan dan dipilih dengan pencahayaan lembut, arah pola cahaya kuat dan jelas, mempertimbangkan level penerangan, serta mampu menunjukkan karakter lanskap. Lampu jalan pada taman memiliki tinggi vertikal 2 meter sehingga pandangan dari pejalan kaki dapat terlihat. Ilustrasi bentuk arbor dan lampu taman yang dapat digunakan tampak seperti pada Gambar 8.

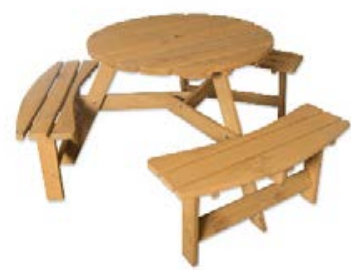

(a)

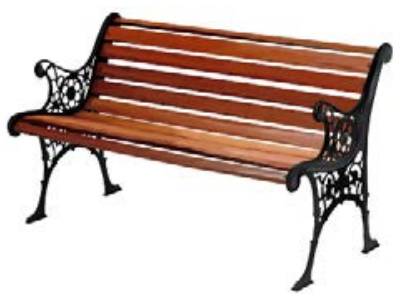

(b)

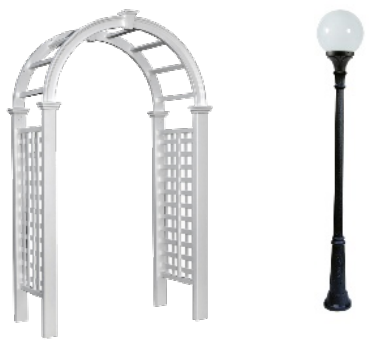

(c)

(d)

Gambar 8. Ilustrasi (a) Meja, (b) Bangku Taman, (c) Arbor, dan (d) Lampu Taman (Sumber: Gardenfurnitureoffers, 2017; Makiskan, 2017; Daphman.com, 2017)

\subsubsection{Desain Konsep Taman Terapi Paru}

Gambar konsep desain taman untuk terapi paru yang direncanakan pada tapak RS Paru Dungus didesain untuk seoptimal mungkin mendukung kegiatan terapi paru bagi pasien. Desain taman dibuat agar secara fungsional selaras dengan program terapi dan sekaligus memiliki nilai estetika. Gambar konsep desain taman terapi untuk pasien paru dapat dilihat pada Gambar 9. 


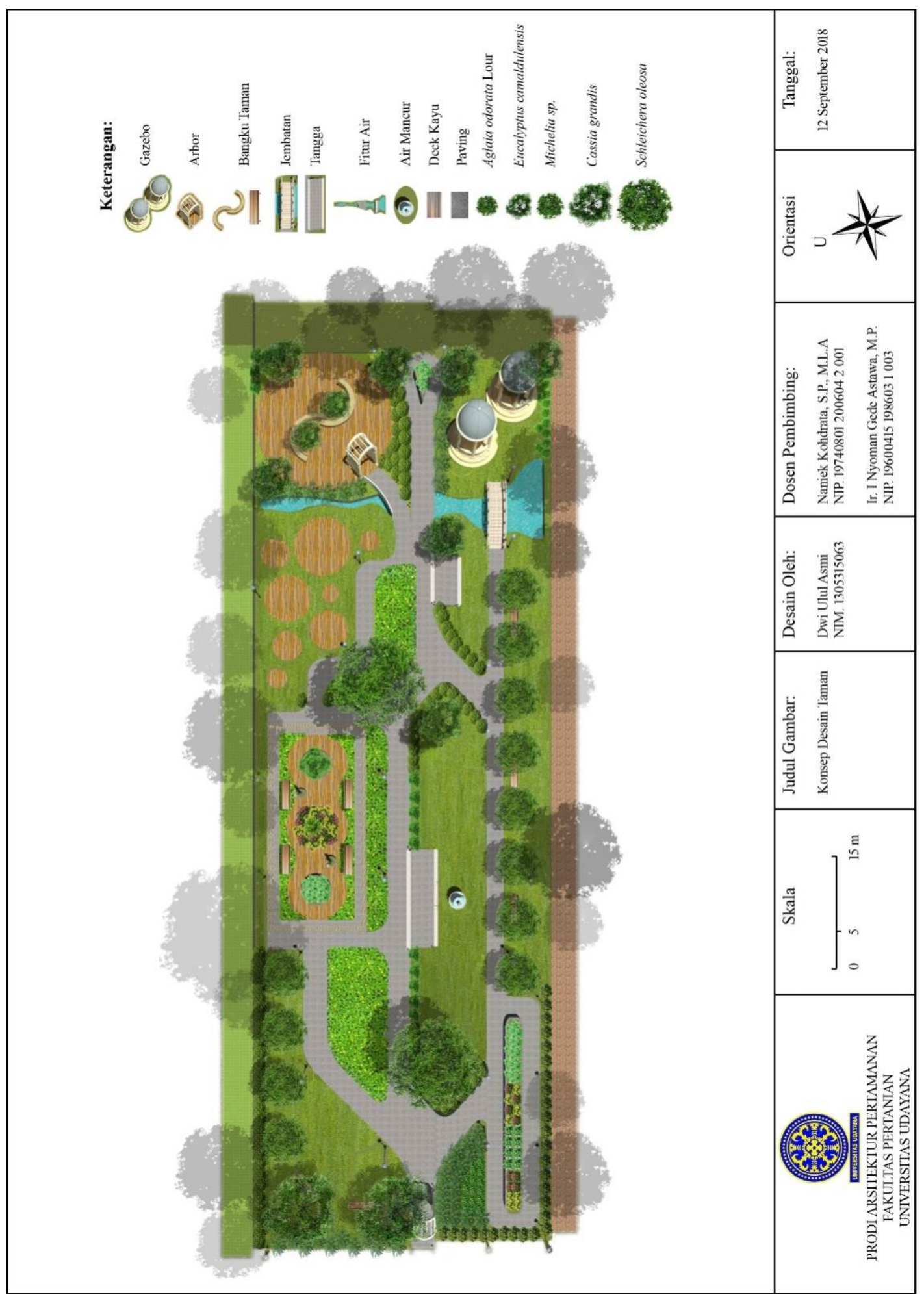

Gambar 9. Desain Konsep Taman Terapi Paru RS Paru Dungus 


\section{Simpulan}

Taman Terapi Paru fokus pada pelepasan stres, meringankan gejala fisik, dan meningkatkan perasaan yang lebih baik bagi pasien, pengunjung, serta pegawai rumah sakit melalui konsep healing environment yang diterapkan melalui prinsip-prinsip desain taman terapi yaitu pergerakan badan dan olahraga, pengalaman merasa mengendalikan, pengalaman bersosialisasi, berinteraksi dengan alam, taman terapi yang terlihat, mudah diakses, memiliki desain yang akrab, tenang, nyaman, dan jelas. Elemen taman yang dapat digunakan berupa elemen keras seperti alat fitness luar ruangan dan elemen lunak seperti air dan tanaman yang mampu merangsang indera melalui warna, aroma, tekstur, dan suara.

\section{Daftar Pustaka}

Azizi, M. A. 1995. Beberapa Sifat Fisik dan Kimia Tanah Latosol (Oxic Dystropept) Parung yang Disawahkan. Jurusan Tanah Fakultas Pertanian. Institut Pertanian Bogor. Bogor.

BPS (Badan Pusat Statistik). 2016. Kabupaten Madiun Dalam Angka 2016. BPS Kabupaten Madiun.

Daphman.com. 2017. Arbors Lowes Canada. Tersedia secara online di http://daphman.com/garden-arborlowes/arbors-lowes-canada-10.html (diakses pada tanggal 31 Oktober 2017).

Dinas Kesehatan Provinsi Jawa Timur. 2012. Profil Kesehatan Provinsi Jawa Timur Tahun 2012. Dinas Kesehatan Provinsi Jawa Timur. Surabaya.

Dines, N. and Brown, K. 2001. Landscape Architect's Portable Handbook. The McGraw-Hill Companies, Inc. United States of America.

Empat Pilar Konsultan. 2016. Masterplan Rumah Sakit Paru Dungus 2016. Madiun.

Garden Furniture Offers. 2017. A Grade Teak 4 Seat Round Bistro Set. Tersedia secara online di http://www.gardenfurnitureoffers.co.uk/garden-furniture (diakses pada tanggal 31 Oktober 2017).

Google Earth. 2018. Rumah Sakit Paru Dungus Madiun Jawa Timur. Citra Digital Globe 2018. (diakses pada tanggal 1 September 2018).

Google Map. 2019. Kabupaten Madiun. Map Data 2019. (diakses pada tanggal 22 Januari 2019).

Hanik, R. 2017. Komunikasi Pribadi. RS Paru Dungus, Dokter Spesialis Penyakit Dalam. Madiun, Indonesia.

Irawan, B. dan Priscilla, T. 2013. Dasar-dasar Desain untuk Arsitektur, Interior Arsitektur, Seni Rupa, Desain Produk Industri dan Desain Komunikasi Visual. Griya Kreasi. Depok.

Jongyun, K. Kiseong, K. Hyesook, J. Chunho, P. 2014. Human Brain Activity and Emotional Responses to Plant Color Stimuli. 39(03):307-315.

Makiskan. 2017. Bench png. Tersedia secara online di https://makiskan.devianart.com/art/Bench-png658716688 (diakses pada tanggal 31 Oktober 2017).

Marcus, C.C. 2007. Healing Gardens in Hospitals. Interdisciplinary Design and Research (IDPR). 1(1):6-13.

Nita, M.U. 2017. Komunikasi Pribadi. RS Paru Dungus, Dokter bagian Fisioterapi. Madiun, Indonesia.

Pokja Sanitasi Kabupaten Madiun. 2011. Buku Puth Kabupaten Madiun. Madiun.

Rachman, Z. 1984. Pertamanan Sebagai IImudan Seni Pencipta Lingkungan Indah dan Berguna. Himagron

Santoso, S. N. 2011. Penggunaan Tanaman Sebagai Pereduksi Pencemaran Udara. Tersedia secara online di http://digilib.its.ac.id//TS-Undergraduate-3100011044172/16616 (diakses pada tanggal 31 Mei 2017). 